\title{
Faktor Risiko Gagal Ginjal Kronik Pada Unit Hemodialisis Rumah Sakit Swasta di Yogyakarta
}

\author{
Irkhamnia Humma Lilia', Woro Supadmi² \\ ${ }^{1}$ Instalasi Farmasi, Rumah Sakit PKU Muhammadiyah Gamping, Yogyakarta 55294 \\ ${ }^{2}$ Bagian Farmasetika, Fakultas Farmasi, Universitas Ahmad Dahlan, Yogyakarta 55164 \\ *Email korespondensi: irkhamniahumma@gmail.com
}

(Submit 15/03/2019, Revisi 05/09/2019, Diterima 20/12/2019)

Abstrak

Gagal ginjal kronik dapat terjadi karena beberapa faktor resiko seperti DM, hipertensi dan gangguan penyakit metabolik lain. Penelitian ini bertujuan untuk mengetahui apakah ada hubungan dan odds ratio antara riwayat hipertensi, riwayat DM, riwayat penggunaan OAINS, riwayat merokok dan riwayat penggunaan minuman suplemen energi dengan kejadian GGK di Rumah Sakit Swasta di Yogyakarta. Penelitian ini menggunakan rancangan case control, yang diambil dari pasien umur 15-75 dengan jumlah sampel sebanyak 92 pasien. Data sekunder diperoleh dari rekam medik pasien dan data primer diperoleh melalui wawancara. Berdasarkan analisis hasil penelitian menggunakan uji chi-square, menunjukkan bahwa hipertensi secara statistik ada hubungan yang bermakna dengan kejadian GGK (OR = 13,988, $\mathrm{p}<0,05 ; \mathrm{Cl}=4,634-$ 42,222 ) yaitu resiko mengalami GGK 13 kali lebih besar dari kelompok kontrol. Riwayat penggunaan OAINS disertai riwayat penyakit faktor risiko GGK juga menunjukkan ada hubungan bermakna dengan kejadian GGK $(\mathrm{OR}=3,556, \mathrm{p}<0,05 ; \mathrm{Cl}=1,500-8,429)$ yaitu memiliki resiko mengalami GGK 3,5 kali lebih besar dari kelompok kontrol. Sedangkan riwayat penyakit $D M(O R=1,230, p>0,05 ; C l=0,347-4,355)$, riwayat merokok $(O R=1,454, p>0,05 ; C l=0,621-3,407)$, riwayat penggunaan minuman suplemen berenergi (OR $=1,190, p>0,05 ; \mathrm{Cl}=0,525-2,697)$ secara statistik menunjukan tidak ada hubungan yang bermakna dengan kejadian GGK. Terdapat hubungan antara riwayat penyakit hipertensi, riwayat penggunaan obat anti inflamasi non steroid disertai riwayat penyakit faktor resiko GGK dengan kejadian GGK. Tidak terdapat hubungan antara riwayat penyakit DM, riwayat merokok, riwayat penggunaan minuman suplemen berenergi dengan kejadian GGK.

Kata kunci: Gagal ginjal kronik, hemodialisis, faktor risiko

\section{Outline}

- Pendahuluan

- Metode

- Hasil dan Pembahasan

- Kesimpulan

- Ucapan Terima Kasih

- Daftar Pustaka 


\section{Pendahuluan}

Gagal ginjal kronik merupakan kerusakan ginjal atau penurunan kemampuan filtrasi glomerulus (Glomerular Filtration Rate/GFR) kurang dari $60 \mathrm{~mL} / \mathrm{min} / 1.73 \mathrm{~m}^{2}$ selama 3 bulan atau lebih yang irreversible dan didasari oleh banyak faktor ${ }^{1}$. Prevalensi gagal ginjal kronik dibeberapa negara cukup tinggi dan meningkat dalam setiap tahunnya. Di Selandia Baru ESRD setiap tahunnya mengalami peningkatan penyebab yang paling umum dari ESRD yaitu Nefropatik diabetik (42\%) diikuti glomerulusnefritis (21\%) dan hipertensi $(12 \%)^{2}$.

Faktor-faktor lain yang diduga berhubungan dengan meningkatnya kejadian gagal ginjal kronik antara lain minuman suplemen energi ${ }^{3}$ dan merokok $^{4-6}$. Dari hasil penelitian faktor-faktor yang diduga berhubungan dengan kejadian gagal ginjal kronik adalah usia, ras, jenis kelamin dan riwayat penyakit keluarga, pemakaian obat analgetik, OAINS dan diabetes $^{2}$.

Dari hasil penelitian diatas, kemungkinan gagal ginjal bisa disebabkan karena riwayat penyakit seperti diabetes, hipertensi maupun penyakit gangguan metabolik lain yang dapat menyebabkan penurunan fungsi ginjal, penyalahgunaan penggunaan obat- obat analgetik dan OAINS baik secara bebas maupun yang diresepkan dokter selama bertahun-tahun dapat memicu risiko nekrosis papiler dan gagal ginjal kronik. Oleh karena itu perlu dilakukan penelitian tentang Faktor Risiko Gagal Ginjal Kronik pada Unit Hemodialisis Rumah Sakit Swasta di Yogyakarta.

Tujuan penelitian ini untuk mengetahui apakah ada hubungan dan odds ratio antara riwayat penyakit faktor risiko GGK, riwayat hipertensi, riwayat DM, riwayat penggunaan OAINS, riwayat merokok dan riwayat penggunaan minuman suplemen energi dengan kejadian GGK di Rumah Sakit Swasta di Yogyakarta.

\section{Metode}

Penelitian yang dilakukan peneliti merupakan penelitian dengan rancangan hospitel based case control study. Sumber data pada penelitian ini diperoleh dengan melakukan wawancara sebagai data primer dan rekam medis pasien sebagai data sekunder untuk mengetahui faktor risiko yang kemungkinan dapat menyebabkan gagal ginjal kronik.

Kasus pada penelitian ini adalah pasien yang terdiagnosis gagal ginjal kronik yang sedang menjalani hemodialisis. Kontrol adalah pasien rawat jalan dan rawat inap yang tidak terdiagnosis gagal ginjal kronik diketahui melalui rekam medik dan wawancara. Kriteria inklusi subyek pada penelitian ini adalah : a) Orang Indonesia b) Usia 15-75 tahun $^{7}$ c) Pasien rawat jalan di poliklinik d) Pasien Gagal ginjal kronik di unit rawat inap selama menjalani hemodialisis pada periode penelitian e) Bersedia berpartisipasi dalam penelitian ini dan kooperatif. Kriteria eksklusi subyek penelitian : a) Pasien Gagal Ginjal Kronik karena keturunan atau herediter berdasarkan wawancara pasien b) Riwayat transplantasi ginjal.

Besar sampel dihitung dengan menggunakan rumus penentuan besar sampel untuk pengujian hipotesis terhadap odds ratio. Total jumlah pengambilan data sebanyak 92 sampel. Analisa data menggunakan program SPSS (Statistical Product and Service 
Solution) dengan tabel $2 \times 2$ dan dianalisis dengan chi-square untuk mengetahui hubungan dan odds ratio riwayat penyakit faktor risiko gagal ginjal kronik, riwayat penyakit hipertensi, riwayat penyakit diabetes mellitus, riwayat penggunaan obat anti inflamasi non steroid, riwayat merokok dan riwayat penggunaan minuman suplemen energi dengan kejadian gagal ginjal kronik.

\section{Hasil dan Pembahasan}

Tabel 1. Hubungan antara beberapa faktor risiko dengan kejadian gagal ginjal kronik di unit hemodialisis Rumah Sakit Swasta di Yogyakarta

\begin{tabular}{|c|c|c|c|c|c|}
\hline \multicolumn{2}{|c|}{ Faktor risiko } & GGK & $\begin{array}{l}\text { NON } \\
\text { GGK }\end{array}$ & $\begin{array}{c}\text { OR } \\
95 \% \mathrm{Cl}\end{array}$ & $p$ value \\
\hline \multirow{2}{*}{ Hipertensi } & Ya & 41 & 17 & 13,988 & \multirow{2}{*}{0,000} \\
\hline & Tidak & 5 & 29 & $(4,634-42,222)$ & \\
\hline \multirow{2}{*}{ Diabetes Melitus } & $\mathrm{Ya}$ & 6 & 5 & 1,230 & \multirow{2}{*}{0,748} \\
\hline & Tidak & 40 & 41 & $(0,347-4,355)$ & \\
\hline \multirow{2}{*}{$\begin{array}{l}\text { OAINS dan } \\
\text { riwayat penyakit }\end{array}$} & Ya & 32 & 18 & 3,556 & \multirow{2}{*}{0,003} \\
\hline & Tidak & 14 & 28 & $(1,500-8,429)$ & \\
\hline \multirow{2}{*}{ Merokok } & Ya & 19 & 15 & 1,454 & \multirow{2}{*}{0,388} \\
\hline & Tidak & 27 & 31 & $(0,621-3,407)$ & \\
\hline \multirow{2}{*}{$\begin{array}{l}\text { Minuman } \\
\text { suplemen }\end{array}$} & Ya & 24 & 22 & 1,190 & \multirow{2}{*}{0,835} \\
\hline & Tidak & 22 & 24 & $(0,525-2,697)$ & \\
\hline
\end{tabular}

\section{A. Riwayat Penyakit Hipertensi}

Hasil analisis crosstab diketahui bahwa variabel hipertensi secara statistik ada hubungan yang bermakna antara hipertensi dengan kejadian gagal ginjal kronik pada pasien dengan hemodialisis (OR $=13,988, p<0,05 ; \mathrm{Cl}=4,634-42,222)$. Secara klinik pasien dengan hipertensi mempunyai peluang atau risiko mengalami gagal ginjal kronik $13 x$ lebih besar dari pasien yang tidak memiliki hipertensi. Hal ini menunjukkan bahwa hipertensi merupakan faktor risiko gagal ginjal kronik dimana tekanan darah di arteri meningkat. Peningkatan ini menyebabkan jantung harus bekerja lebih keras dari biasanya untuk mengedarkan darah melalui pembuluh darah. Ginjal merupakan salah satu pusat pengaturan tekanan darah sehingga apabila tekanan darah tinggi terjadi terus-menerus melebihi normal $>140 / 90 \mathrm{mmHg}$ maka kondisi ini dapat mempengaruhi ginjal (hipertensi sekunder).

Hipertensi pada gagal ginjal kronik dapat disebabkan oleh beberapa hal yakni 1). Retensi natrium, 2). Peningkatan sistem RAA akibat iskemi relatif karena kerusakan regional, dimana RAA (Renin Angiotensinogen Aldosteron) sistem berperan penting dalam memelihara hemodinamik dan homeostasis kardiovaskuler. Sistem RAA dianggap sebagai suatu homeostatic feed back loop dimana ginjal dapat mengeluarkan renin sebagai respons terhadap rangsangan seperti tekanan darah rendah, stres simpatetik, berkurangnya volume darah, 3). Aktivitas saraf simpatis meningkat akibat kerusakan ginjal, 4). Hiperparatiroid Sekunder, 5). Pemberian eritropoetin ${ }^{8}$.

\section{B. Riwayat Penyakit DM}

Hasil analisis crosstab diketahui bahwa variabel diabetes mellitus secara statistik tidak ada hubungan yang bermakna antara diabetes mellitus dengan kejadian gagal ginjal 
kronik pada pasien dengan hemodialisis ( $\mathrm{OR}=1,230, \mathrm{p}>0,05 ; \mathrm{Cl}=0,347-4,355)$. Secara klinik pasien dengan diabetes mellitus mempunyai peluang atau risiko mengalami gagal ginjal kronik 1,2x lebih besar dari pasien yang tidak memiliki diabetes mellitus sehingga dapat disimpulkan bahwa diabetes mellitus merupakan faktor risiko gagal ginjal kronik.

Pada penyakit diabetes melitus terjadi gangguan pengolahan glukosa dalam darah oleh tubuh, yang lama - kelamaan dapat menyebabkan kerusakan pada ginjal dan akhirnya dapat menjadi penyakit ginjal kronik. Kadar glukosa yang tinggi dalam darah tersebut, bila tidak terkontrol dapat merusak pembuluh darah ginjal dalam kurun bertahun tahun sehingga menurunkan kemampuan ginjal untuk menyaring darah dan membuang produk sisa di urin .Gangguan ginjal pada penderita diabetes melitus dan hipertensi bukan karena obat - obatan yang dikonsumsi. Namun karena kadar gula darah yang kerap tidak terkontrol secara menahun merusak pembuluh darah ginjal ${ }^{8}$.

\section{Riwayat penggunaan OAINS dan riwayat penyakit faktor risiko GGK}

Berdasarkan hasil analisis crosstab diketahui bahwa penggunaan OAINS dan mempunyai riwayat penyakit faktor risiko GGK secara statistik ada hubungan yang bermakna dengan kejadian gagal ginjal kronik pada pasien dengan hemodialisis (OR = 3,556, $\mathrm{p}<0,05 ; \mathrm{Cl}=1,500-8,429$ ), secara klinik riwayat penggunaan OAINS dan mempunyai riwayat penyakit faktor risiko GGK mempunyai peluang atau risiko mengalami gagal ginjal kronik 3,5 kali lebih besar dari yang tidak menggunakan OAINS dan mempunyai riwayat penyakit faktor risiko gagal ginjal kronik.

Mekanisme kerja OAINS menghambat sintesis prostaglandin. Prostaglandin $\mathrm{PGE}_{2}$ dan $\mathrm{PGI}_{1}$ merupakan vasodilator kuat yang masing - masing disintesis dalam medula ginjal dan glomerolus, dan terlibat dalam pengendalian aliran darah ginjal serta ekskresi garam dan air. Inhibisi sintesis prostaglandin ginjal bisa menyebabkan retensi natrium, penurunan aliran darah ginjal, dan gagal ginjal terutama pada pasien dengan kondisi yang berhubungan dengan pelepasan katekolamin dan vasokonstriktor dan angiotensin II (misalnya gagal jantung kongestif, sirosis). Selain itu, OAINS bisa menyebabkan nefritis interstisial dan hiperkalemia. Penyalahgunaan analgesik jangka panjang selama bertahun - tahun berkaitan dengan nekrosis papiler dan gagal ginjal kronik ${ }^{9}$.

\section{Riwayat Merokok}

Hasil analisis crosstab diketahui bahwa variabel merokok secara statistik tidak ada hubungan bermakna antara merokok dengan kejadian gagal ginjal kronik pada pasien dengan hemodialisis $(\mathrm{OR}=1,454, \mathrm{p}>0,05 ; \mathrm{Cl}=0,621-3,407)$. Namun secara klinik merokok mempunyai peluang atau risiko mengalami gagal ginjal kronik $1,4 \times$ lebih besar dari pasien yang tidak memiliki riwayat merokok. Dapat disimpulkan bahwa merokok merupakan salah satu faktor risiko yang dapat mempengaruhi kejadian gagal ginjal kronik

Efek merokok pada fase akut yaitu meningkatkan pacuan simpatis yang akan berakibat pada peningkatan tekanan darah, takikardia dan penumpukan katekolamin dalam sirkulasi. Pada fase akut beberapa pembuluh darah juga sering mengalami vasokontriksi misalnya pada pembuluh darah koroner, sehingga pada perokok akut 
sering diikuti dengan peningkatan tahanan pembuluh darah ginjal sehingga terjadi penurunan laju filtasi glomerulus dan fraksi filtrasi. Pada perokok kronik terjadi penurunan aliran darah ginjal, tetapi tidak menurunkan GFR, karena terjadi peningkatan kadar endotelin plasma. Pada perokok kronik akan terjadi peningkatan metabolisme prostaglandin, sehingga terjadi peningkatan tromboksan dan isoprostan, peningkatan kadar NO, peningkatan agregasi trombosit, peningkatan PMN dan monosit juga mengalami albuminuria. Pada perokok kronik terjadi toleransi terhadap nikotin sehingga kadar NO tetap tinggi dan effective renal plasma flow (ERPF) tetap normal ${ }^{6}$.

\section{E. Riwayat Minuman Suplemen Berenergi}

Hasil analisis crosstab diketahui bahwa variabel merokok secara statistik tidak ada hubungan bermakna antara minuman suplemen dengan kejadian gagal ginjal kronik, hal ini disebabkan karena perbandingan subyek penelitian penggunaan suplemen hampir sama untuk matching subyek penelitian $(\mathrm{OR}=1,190, \mathrm{p}>0,05 ; \mathrm{Cl}=0,525-2,697)$. Namun secara klinik penggunaan minuman suplemen mempunyai peluang atau risiko mengalami gagal ginjal kronik $1 x$ lebih besar dari pasien yang tidak menggunakan minuman suplemen. Sehingga dapat disimpulkan hasil yang diperoleh menunjukkan bahwa risiko untuk mengalami kejadian CKD secara bermakna lebih tinggi pada pengkonsumsi minuman suplemen dari pada yang tidak mengonsumsi minuman suplemen.

Beberapa psikostimulan (kafein dan amfetamin) terbukti dapat mempengaruhi fungsi ginjal. Amfetamin dapat menyempitkan pembuluh darah arteri ke ginjal sehingga darah yang menuju ke ginjal berkurang akibatnya ginjal akan kekurangan asupan makanan dan oksigen. Keadaan sel ginjal kekurangan oksigen dan makanan akan menyebabkan sel ginjal mengalami iskemia dan memacu timbulnya reaksi inflamasi yang dapat berakhir dengan penurunan kemampuan sel ginjal dalam menyaring darah ${ }^{10}$.

\section{Kesimpulan}

1. Terdapat hubungan antara riwayat penyakit hipertensi $(\mathrm{OR}=13,988, \mathrm{p}<0,05 ; \mathrm{Cl}=$ $4,634-42,222$ ), riwayat penggunaan obat anti inflamasi non steroid dan riwayat penyakit faktor risiko GGK $(\mathrm{OR}=3,556, \mathrm{p}<0,05 ; \mathrm{Cl}=1,500-8,429)$ dengan kejadian gagal ginjal kronik.

2. Tidak terdapat hubungan antara riwayat penyakit diabetes mellitus dengan kejadian gagal ginjal kronik $(\mathrm{OR}=1,230, \mathrm{p}>0,05 ; \mathrm{Cl}=0,347-4,355)$.

3. Tidak terdapat hubungan antara riwayat merokok $(O R=1,454, p>0,05 ; \mathrm{Cl}=0,621$ $3,407)$, riwayat penggunaan minuman suplemen berenergi $(O R=1,190, p>0,05 ; \mathrm{Cl}$ $=0,525-2,697)$ dengan kejadian gagal ginjal kronik.

\section{Ucapan Terimakasih}

Penelitian ini dapat diselesaikan dengan adanya dukungan, bimbingan dan bantuan dari berbagai pihak, oleh karena itu pada kesempatan ini penulis mengucapkan terima kasih kepada:

1. Woro Supadmi, M.Sc., Apt. yang telah membimbing, membantu dan memberi masukan selama penyusunan penelitian ini.

2. Bu Novi dan bagian rekam medis Rumah Sakit, yang telah membantu dalam penelitian sehingga penulis dapat menyelesaikan penelitian ini. 


\section{Daftar Pustaka}

1. National Kidney Foundation, 2002, K/DOQI Clinical Practice Guidelines for Chronic Kidney Disease: Evaluation, Classification, and Stratification

2. Mcclellan, W.M. dan Flanders, W.D., 2003, Risk Factor for progressive chronic kidney disease; J Ant Soc Nephrol;14:s65-s70

3. Sulaiman, M.E., Barancy, P., Divino, J.C., Lindholm, B., Bergstrom, J., 2002, Acumulation of taurine in patients with renal failure, Nephrol Dial Transplant

4. Baggio,B,. Budakovic,A.,Dalla, M., Saller,A., Bruseghin, M., Fioretto,P, 2002, Effects of cigarrete smoking on glomerular structur and function in tipe 2 dibetic patients, J AM Soc Nephrol, 13:2730-2746

5. Ejerblad, E., Fored, C.M., Lindblad, P., Fryzek, J., Dikman, P.W., 2004, Association between smoking and chronic renal failure in a nationwide population-based case control study; J Am Soc Nephrol; 15: 2178-85

6. Orth, S.R., Ogata, H., Ritz, E., 2000, Smoking and kidney; Nephrol Dial Transplant; 15:1509 - 11

7. Fored,C.M., Ejerblad,E., Lindblad,P., Fryzek,J.P., Dickman,P.W., Signorello,L.B., Lipworth, L., Elinder,C.G., Blot,W.J., McLaughlin,J.K., Zack,M.M., 2001.Acetaminophen, aspirin, and chronic renal failure, $N$ Engl $J$ Med 20;345(25):1801-8

8. Sudoyo, A.W., et al., (2006). Buku Ajar Ilmu Penyakit Dalam Jilid I. Edisi Keempat. Jakarta: Pusat Penerbitan Departemen IImu Penyakit Dalam FKUI

9. Neal, M.J., 2006, At a Glance Farmakologi Medis edisi ke 5, Jakarta : Erlangga

10. Hidayati, T., 2008, Hubungan antara hipertensi, merokok, dan minuman suplemen energi dan kejadian penyakit ginjal kronik di RSU PKU Muhammadiyah Yogyakarta, case control study, Tesis, Epidemiologi IKM, UGM 